$$
\begin{gathered}
\text { 연령별 시민참여형 도시공원 관리의지 비교 연구 } \\
\text {-인천광역시 도시공원을 대상으로- } \\
\text { 유재섭" · 이재호** } \\
\text { "서울시립대학교 조경학과 대학원생 · "서울시립대학교 조경학과 조교수 }
\end{gathered}
$$

\title{
A Comparative Study on Willingness to Manage Urban Parks by Age - Focusing on the Case of Incheon City Park -
}

\author{
Yoo, Jae Seop* $\cdot$ Lee, Jae Ho* \\ *Graduate Student, Dept. of Landscape Architecture, College of Urban Science, University of Seoul \\ ${ }^{* *}$ Assistant Professor, Dept. of Landscape Architecture, College of Urban Science, University of Seoul
}

\begin{abstract}
For urban parks' rational and efficient management, research on creating green spaces in living area through citizen participation is continuously being conducted. However, in existing studies, citizens are recognized as a homogeneous group, and research on the intention to participate in park management according to user characteristics has not been conducted. A few studies have attempted to show differences through conceptual variables, such as user satisfaction and attachment to parks, but studies on sociodemographic factors, such as the users' age, have not been conducted. This study was conducted to ascertain the differences in preferred parks and park management participation methods by age, targeting various parks located in ten districts of Incheon Metropolitan City. Regression analysis was performed after collecting 1,226 questionnaires, applying a population-proportional allocation in the ten districts. As a result of the study, it was found that the difference according to the age of users has the most influence on the willingness to manage the park rather than the satisfaction or other factors. Also, a chi-square analysis was conducted to find the differences in preferred urban parks and management methods by age. The results showed that the choice to manage parks was statistically higher for those in their 50s or older, and the differences in preferred park types and desired park greening methods suggested implications for park management plans by age.
\end{abstract}

Key Words: Park Management, Preferred Park, Age Group, Park Satisfaction, Willingness to Participate

Corresponding author: Jae Ho Lee, Assistant Professor, Dept. of Landscape Architecture, College of Urban Science, University of Seoul, Seoul 02504, Korea, Tel.: +82-2-6490-2842, E-mail: jaeho19@uos.ac.kr 


\section{국문초록}

도시공원의 합리적이고 효율적인 관리를 위해 시민참여를 통한 생활권 녹지 조성방안에 대한 연구가 지속적으로 이뤄지고 있지만, 기존의 연구에서는 시민을 동일한 성격의 집단으로 인식하고 이용자의 특성 차이에 따른 공원관리 참여에 대한 연구는 진행되지 않고 있다. 특히 기존의 연구는 이용자의 만족도나 애착심과 같은 개념적인 변수를 통한 차이만 보고자 하였고, 이용자의 연령과 같은 사회인구학적 요소에 대한 연구는 아직까지 수행되지 않고 있다. 이러한 연구의 한계점을 가지고 본 연구는 인천광역시의 10 개 구· 군에 광역적으로 존재하는 도시공원을 대상으로 연령별 선호 하는 공원과 공원관리 참여방법의 차이에 대한 연구를 진행하였다. 인천시 거주주민과 공무원을 대상으로 하였고, 10 개 구 - 군에 인구 비례 할당을 적용하여 총 1,226 부의 설문을 걷어 회귀분석을 수행하였다. 연구결과, 만족도 및 다른 요인보 다 이용자의 연령에 따른 차이가 공원관리 의지에 가장 영향을 많이 미친다는 결과를 얻었고, 이를 바탕으로 연령별 선호하는 도시공원 및 관리방법 차이를 알아내기 위해 카이스퀘어 분석을 수행하였다. 연구 결과, 젊은층보다는 50 대 이상의 연령층이 공원관리 의지가 통계적으로 높음이 확인되었으며 선호하는 공원유형과 희망하는 공원녹지화 방법에 대한 차이를 통해 연령별 공원관리방안에 대한 시사점을 제시하였다.

주제어 : 공원관리, 선호하는 공원, 연령대, 공원만족도, 참여의지

\section{I. 서론}

시민참여를 중심으로 한 거버넌스가 점차 보편화됨에 따라 각 지자체는 시민참여를 통한 도시공원의 운영 및 관리방안을 강조하고 있다(Kim, 2012; Ly and Xiao, 2016). 시민참여를 통 한 공원관리 시 지자체에서 제공해야 하는 인력과 비용을 절감 하려는 부분도 있지만(Byeon et al., 2011), 근본적으로는 공원 거버넌스는 주민참여를 통해 시민들의 참여의식을 향상시키고, 지역 애착심 강화를 통해 지역공동체 문화를 활성화하고 지속 가능한 공원을 유지하고자 함에 있다(Kim et al., 2009; Yoon and Kim, 2020).

이러한 시민참여의 다양한 장점으로 많은 지자체는 시민참 여 활성화를 통한 도시공원 및 녹지관리 방안을 모색하려고 있 다(Son, 2011). 학술적으로는 시민참여를 증진시키고자 하는 방법에 대한 연구가 많이 진행되었는데, $\mathrm{Kim}$ and $\mathrm{Nam}(2019)$ 의 연구에서는 시민들의 애착심을 증진시켜 주민참여 및 관리 의지를 높이고자 하는 연구를 진행하였으며, $\operatorname{Park}(2012)$ 의 연 구에서는 지역공동체 소속감을 바탕으로 주민참여 방안을 모 색하는 연구를 진행하였다. 학술적 연구결과에 따라 실질적으 로도 시민을 위한 다양한 프로그램이 공원에 편성되거나 시민 들의 의견을 반영한 시설들이 설치되는 등 공원 조성 계획 시 시민의 요구를 반영하는 정책이 시행되고 있다( $\mathrm{Ha}, 2020)$.

이토록 시민참여와 시민주도, 그리고 민관 거버넌스의 중요 성이 광범위하게 부상하고, 공원 거버넌스 구축을 위한 방안도 학술적으로 다양하게 연구되고 있지만(Kwon et al., 2011; $\mathrm{Kim}$ and Lee, 2019), 여전히 과도한 공공중심의 공원 관리실 태를 벗어나지 못하고 있는 실정이다(Kim, 2003). 주민의 참여
가 절실하게 요구되는 공원 거버넌스 구축에서 실질적 시민참 여는 제한된 참여로만 이뤄지는 경우가 대부분이고(예: 공청 회, 설문조사), 계획수립 이전단계에서 실질적인 참여의 부재 등 시민참여가 형식적으로만 이뤄지고 있는 실정이다 $(\mathrm{Km}$, 2015). 이는 그동안 시민참여 연구가 많이 진행되었음에도, 시 민들을 다른 특성을 지닌 사람들의 집합으로 인식하지 않고, 일반화시키거나 동일한 특성을 지닌 집단으로 인식하는 문제 점에 기인한다(Sundevall and Jansson, 2020). 공원관리에 있어 주민참여를 강화하기 위해 기존 연구에서도 이용자를 구분하 여 특성에 따른 관리방안을 제시한 몇몇 연구는 있었지만(Kim and Lee, 2019), 아직까지 공원이용자의 연령에 따른 공원 운 영관리 참여 차이 및 인식에 관한 연구는 부재한 실정이다.

해외 연구에서는 연령별 차이를 포함한 도시공원 이용자의 사회경제적 차이에 따른 도시공원 이용관련 연구가 활발하게 진행되고 있다. 연령대별 차이에 따른 공원의 접근성 차이에 대 한 연구가 많이 진행되고 있으며(Subramanian and Jana, 2018; Guo et al., 2019), 최근의 연구에서는 공원의 접근성 개선 및 유 니버설 디자인을 통해 노인인구의 공원 이용이 증진된다는 연구 도 수행되고 있다(Wen et al., 2020). 즉, 연령대별 차이에 따라 도시공원 이용빈도 및 접근성 등 도시공원의 이용에 있어 차이 가 발생하며 이는 도시공원 관리방안에 시사점을 제공해 줄 수 있다.

도시공원의 합리적이고 효율적인 관리를 위해서는 공원을 이용하는 시민의 참여가 필수적이며(Son and Yoon, 2002; Bae and Kim, 2013), 시민참여를 위해서는 시민들의 연령 및 특성 에 따른 차별화된 전략을 통해 공원 관리 참여에 주요한 요인 을 찾고, 이를 바탕으로 공원 관리 참여 활성화 방향을 제시해 
야 한다. 따라서 본 연구는 첫째, 시민참여를 향상시키기 위해 서 어떠한 요인이 시민참여에 영향을 미치는지 알아보고, 특히 이용자의 연령에 따른 공원운영 참여의지 및 인식 차이를 통해 연령별 공원운영 관리 방안을 모색하고, 둘째로 연령대에 따른 공원관리 선호방안의 차이점을 살펴보고자 함에 있다.

이를 수행하기 위해 본 연구에서는 특정 일부 공원을 대상지 로 선정하여 연구결과를 일반화시키는 것이 아닌, 광역적 스케 일인 인천광역시의 10 개 구 · 군에 존재하는 공원 이용자를 대 상으로 하여 보다 보편적으로 시민의 공원관리 참여의지에 미 치는 영향을 파악하고자 하였다. 본 연구 결과는 인천시와 같 은 광역적인 도시에 공원을 관리함에 있어 정책적 시사점을 제 공해 줄 수 있을 것으로 판단한다.

\section{II. 문헌연구}

\section{1. 사회인구학적 요인과 공원운영 - 관리}

해외의 연구에서는 연령, 소득, 교육수준 등과 같은 사회인 구학적 요인에 따라 공원의 선호 및 관리의지가 다르다는 연구 결과가 최근에 많이 보고되고 있다. Mertens et al.(2019)의 연 구는 청소년들과 공원이용에 대한 연구를 진행하였는데, 청소 년집단에서 공원의 유지관리상태가 공원의 선호도를 결정하는 가장 중요한 요소라고 언급하였고, 그 다음에 공원이용시설의 유무 및 관리상태가 중요하다고 보고하고 있다. 다른 연구에서 는 이용자 연령층에 따른 차이를 연구한 다른 문헌에서는 이용 자층을 어린이, 청소년, 노년층 세 집단으로 구분하여 연령대별 로 공원에서의 선호요소와 관리참여의지를 높이기 위한 제안 을 하고 있다(Sundevall and Jansson, 2020). 연령층 외에도 da Schio et al.(2021)의 연구에서는 코로나19 감염병 상황에서 이 용자의 교육수준 및 소득수준이 높은 사람이 공원이용을 더 빈 번하게 한다는 연구결과를 발표하는 등 사회인구학적 요소가 공원 이용 및 선호도, 공원관리참여의도에까지 영향을 미친다 는 연구결과를 제시하고 있다.

국내 연구에서는 성별·연령대별 · 직업별 - 소득별 - 거주기 간별 등 여러 사회인구학적 요인들이 공원의 운영에 어떤 식으 로 영향을 미쳤는지에 대한 많은 연구가 진행되지는 않았지만, 몇몇 연구에서는 이러한 사회인구학적 요인이 공원운영관리에 미치는 영향력에 대해 연구하였다. 예를 들어, 서울숲 자원봉사 자들의 성별이나 연령대별 등 개인적 특성에 따른 참여 동기의 차이를 보고자 연구를 진행한 Lee(2013)의 연구에서 남성 또 는 청년층은 외면적인 부분(예: 학점 - 취업·경력 등)이 참여 동기에 영향을 미치고, 이와 대조적으로 여성 또는 중·장년은 내면적인 부분(예: 자아실현, 배움 - 성숙 등)이 참여 동기로 자원봉사에 참여하고 있음을 보여주어 연령과 성별에 따라 참
여의지에 차이가 있다는 것을 밝혀내었다. 또한 Kim and Lee(2019)의 연구에서는 한강공원을 이용하는 시민들을 개 인 - 친구·가족 단위 등 세 집단으로 분류하여 이용집단별 차 이를 보고자 하였고, 연구결과 개인 집단은 도보나 자전거 진 입 관련에, 가족 집단은 놀이터 등의 휴게시설이 공원 운영 및 관리에 큰 영향을 미친다고 하여, 집단 간 중요하게 생각하는 부분에 있어 차이가 발생한다는 것을 보여주었다. 이 연구들과 비슷하게 주민참여형 공원의 조성 경험의 여부가 공원 관리 및 참여 태도에 어떠한 영향을 미치는지를 연구한 $\mathrm{Cho}$ (2012)의 논문에서는 공원 조성 경험이 있는 주민은 그 공원에 높은 장 소 애착을 형성하고, 그것이 공원 관리 및 참여 태도에 긍정적 인 영향을 미친다고 하여 공원의지를 높이려면 장소애착이 높 아야 함을 밝혀주었다. 이러한 연구들은 사회인구학적 요소가 공원이용 및 관리의지에 영향을 미친다는 연구결과를 제시하 고 있지만, 아직 공원의 연령대별 차이에 따른 공원관리의지 차이에 대한 연구는 진행되고 있지 않다.

\section{2. 공원이용 만족도와 공원운영 · 관리}

공원 이용 만족도에 따른 공원운영관리에 대한 연구는 기존 연구에서 많이 수행되었다. 예를 들어, 영국에서 시행하고 있는 커뮤니티 주도형 거버넌스를 통한 공원 관리를 평가하기 위해 $\mathrm{Nam}$ and $\operatorname{Kim}$ (2019)은 사회경제적으로 불리한 지역인 영국 셰필드의 2 개 공원을 대상으로 이용자 설문조사를 시행한 결 과, 공원청결도 및 공원발전의 변화가 이용자들의 공원 관리 만족도를 높게 평가한다고 제시하였다. 이러한 연구의 연장선 상에서 사람들의 심리적 만족도의 향상이 공원관리의지에 영 향을 미쳐 지속적으로 공원관리에 기여할 수 있다고 하였다. 또한 $\mathrm{Kim}$ et al.(2010)의 연구에서는 안양시에 존재하는 여러 도시공원 이용자들을 대상으로 이용자의 공원 만족도 및 녹지 환경의 평가에 기반한 설문조사를 실시하였고, 연구결과 백만 그루 나무 심기 등 다양한 참여 프로그램에 의한 결과로 시민 들의 만족도가 1999년에 비해 2007년에 긍정적으로 향상되었 다고 보고하였다. 그리고 이러한 결과는 연쇄적으로 공원 이용 자 간 교류에 의한 시민운동 등 이용자들의 공원 운영 및 관리 참여의지를 증진시키는 데도 영향을 미친다고 설명하고 있다. 공원이용 만족도와 공원운영관리를 보고자 한 Lee(2021)의 연 구에서는 2014년과 2020년 두 시점의 양주시 내 존재하는 여러 공원 이용자를 대상으로 연구하여 공원이용 만족도와 공원관 리의지의 연관관계에 대해서 연구하였다. 연구결과, 통계적으 로 이용만족도와 이용관리의지간의 통계적 유의성이 밝혀지긴 하였으나, 이것이 꼭 공원이용 빈도에 따라 만족도가 정비례로 올라가는 것은 아니라는 것을 밝혀내어 공원관리의지 향상에 공원에서의 만족도가 결정적 요인이 아니라는 것을 밝혀내었 
다(Lee, 2021). 이처럼 공원 이용자 만족도에 따른 공원 조성 및 관리의 시민참여 의지와 관련된 연구는 지속적으로 연구되 며 만족도와 공원운영 관리상의 연관성에 대해서는 언급하고 있지만, 만족도에 영향을 미치는 세부적인 요소에 대한 연구는 부족하다. 또한 만족도가 관리의지에 결정적 영향을 미치는 요 소가 아니라는 점에서 만족도 외의 다른 변수를 통한 공원관리 의지를 높일 수 있는 변수의 연구가 필요하다. 따라서 본 연구 에서는 사회인구학적 요인과 더불어 이용자의 만족도 조사항 목을 바탕으로 시민들의 공원녹지 운영관리 방안 모색에 있어 주요한 요인을 찾고자 한다.

\section{III. 연구의 방법}

\section{1. 대상지 소개}

본 연구의 대상지인 인천광역시는 서울에서 서쪽으로 $40 \mathrm{~km}$ 떨어져 있는 수도권 서북부에 자리 잡고 있으며 300 만 명 이상 의 인구가 거주하고 있는, 전국에서 3 번째로 인구가 많은 도시 이다. 연안에 위치하여 개항에 따른 도시화가 급격하게 진행된 인천광역시는 원인재·보문사· 전등사· 을왕리해수욕장 · 실미 해수욕장 - 마니산 등 풍부한 역사문화 및 레크레이션 자원이 분 포하며, 인천공항 등 교통의 요충지로써 해외 관광객들이 첫발 을 내딛는 지역으로 유명하다.

인천광역시는 최근 급속한 시가지 확산과 대규모 지역 개발 사업이 진행 중에 있으며, 현재 1 인당 공원 · 녹지 지정, 조성면 적 비교 결과, 지정면적은 계획 목표치의 약 $82 \%$ 이고, 조성면 적은 목표치의 약 $44 \%$ 로 계획수치 대비 저조한 공원 - 녹지 조 성율을 보이고 있으며 보전, 확충, 복원 계획은 계획대비 그 실 현이 부족한 실정이다. 더불어 가로수, 녹도, 생태통로, 자전거 도로, 경관도로 계획 등도 계획대비 조성이 저조한 실태이다. 게다가 1 인당 도시공원 면적 비율도 10 개 구·군별로 차이가 상당히 많이 나며 서해안쪽에 위치하여 미세먼지 취약성이 높 은 지역이 많다. 인천시의 대부분 공원이 1980 90년대 집중하 여 조성된 공원이기 때문에 시민참여를 통한 공원의 개선 및 지속적인 관리가 타 지역보다 중요하다는 점을 인천시에서도 인식하여 시민참여 고양을 통한 도시공원의 확충 및 관리방안 을 매 5년마다 방안을 강구하고 있다. 하지만, 실질적으로 시민 들이 참여해서 공원을 관리하는 형태가 유지되고 있지는 못한 실정이라는 점에서 인천광역시 시민참여형 공원녹지관리 방안 을 제시해 줄 수 있다는 점에서 인천광역시의 도시녹지를 연구 대상지로 설정하여 연구를 진행하였다.

\section{2. 자료수집}

본 연구는 특정 공원만을 대상지로 선정했을 경우의 지역적 특이성이 반영되는 등의 오류를 최소화하고자 인천광역시 10 개 구·군에 광역적으로 존재하는 여러 공원을 대상으로 하여 연구를 진행하였다. 또한 연령대별 공원관리의지의 차이를 균 등하게 보기 위해 행정안전부에서 제공하는 총인구수를 바탕 으로 비례할당추출(quota sampling)을 수행하여 조사하였다. 구체적으로는 인천시 총 10 개의 구·군별 행정구역으로 중구, 동구, 미추홀구(남구), 연수구, 남동구, 부평구, 계양구, 서구, 강화군, 옹진군으로 구분하여 설문을 통해 주민의 공원녹지 이 용행태를 조사하였고, 각 지역·연령대별로 의견을 고르게 수 렴하고자 인천시 주민 설문 응답자의 거주지 조사를 통해(행정 안전부의 주민등록인구통계 2021년 1월 기준의 비율을 기준) 1,000 명 (연령대별×구별) 기준으로 비례 할당을 수행하여 조사 하였다(Table 1 참조).

설문 대상자는 인천시민과 공무원을 대상으로 설문조사를 실시하였다(공무원은 도시공원 관련 업무에 종사하는 공무원 이 아닌 시청, 군청 등 관공서에 근무하는 공무원으로 인천시 민과 차이가 없었음). 조사내용으로는 공원녹지의 전반적 만족 도, 이용실태 및 평가, 공원 관리 및 시민참여방안 및 이용자의 일반적 특성으로 구성하였다(Table 2 참조). 본 연구는 구조화 된 설문지를 이용하여 조사원이 각 지역의 주민센터와 근린공

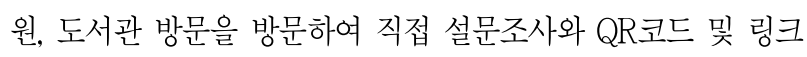
를 이용한 온라인 조사를 병행하여 자료를 수집하였다. 온라인 설문은 인천광역시 홈페이지에 노출시켜 최대한 응답부수를 높이려고 하였고, 노인층의 응답률이 온라인상 많이 떨어지기 때문에 면접원을 이용한 1 대 1 개별면접 방법을 수행하였다. 대상자 선정은 구군별 인구대별 필요한 인원안에서 임의로 대 상자를 선정하여 진행하였고, 응답자 자기 기입 방식(self administrated survey)을 사용하였다. 설문 기간은 2021년 3월 17 일부터 4 월 27 일까지 약 6 주간 수집되었고, 불성실한 설문지 를 제외한 유효 표본 수는 대면 824부와 온라인 402부(일반시 민: 186 부, 공무원 및 교사: 216 부)를 수집하여 총 1,226 부를 수집, 통계분석에 활용하였다.

\section{3. 설문지 구성 및 변수의 측정}

설문지 구성은 크게 네 파트로 구분하여 조사하였다(Table 2 참조). 각 파트의 세부 항목은 인천시 공원조성과에서 5 년 단 위로 조사하고 있는 공원녹지 개선을 위한 시민 설문조사 설문 지를 기본으로 제작하였다.

설문지의 첫 번째 파트에서는 인천시 공원녹지 이용실태를 파악하기 위해 자주 이용하는 공원 - 이용 빈도·주된 이용 시 
Table 1. Comparison of proportional allocation by district and county in Incheon

\begin{tabular}{|c|c|c|c|c|c|c|c|c|}
\hline \multicolumn{2}{|c|}{$\begin{array}{l}\text { Proportional allocation } \\
\text { (Based on 1,000 people) }\end{array}$} & \multirow{2}{*}{$\begin{array}{c}\begin{array}{c}14 \sim 19 \\
(10 \mathrm{~s})\end{array} \\
3\end{array}$} & \multirow{2}{*}{$\begin{array}{c}\begin{array}{c}20 \sim 29 \\
(20 \text { s })\end{array} \\
8\end{array}$} & \multirow{2}{*}{$\begin{array}{c}\begin{array}{c}30 \sim 39 \\
(30 \mathrm{~s})\end{array} \\
9\end{array}$} & \multirow{2}{*}{$\begin{array}{c}\begin{array}{c}40 \sim 49 \\
(40 \mathrm{~s})\end{array} \\
11\end{array}$} & \multirow{2}{*}{$\begin{array}{c}\begin{array}{c}50 \sim 59 \\
(50 \mathrm{~s})\end{array} \\
9\end{array}$} & \multirow{2}{*}{$\frac{60 \text { s or older }}{6}$} & \multirow{2}{*}{$\frac{\text { Total }}{46}$} \\
\hline Jung District & Assignment & & & & & & & \\
\hline (중구) & Collection & 4 & 8 & 12 & 16 & 11 & 9 & 60 \\
\hline \multirow{2}{*}{$\begin{array}{l}\text { Dong District } \\
\text { (동구) }\end{array}$} & Assignment & 2 & 2 & 3 & 4 & 4 & 4 & 19 \\
\hline & Collection & 1 & 3 & 8 & 4 & 6 & 3 & 25 \\
\hline \multirow{2}{*}{$\begin{array}{l}\text { Michuhol District } \\
\text { (미추홀구(남구)) }\end{array}$} & Assignment & 8 & 25 & 24 & 27 & 28 & 25 & 137 \\
\hline & Collection & 8 & 29 & 32 & 30 & 36 & 22 & 157 \\
\hline \multirow{2}{*}{$\begin{array}{l}\text { Yeonsu District } \\
\text { (연수구) }\end{array}$} & Assignment & 10 & 23 & 25 & 30 & 28 & 17 & 133 \\
\hline & Collection & 11 & 31 & 32 & 48 & 46 & 15 & 183 \\
\hline \multirow{2}{*}{$\begin{array}{l}\text { Namdong District } \\
\text { (남동구) }\end{array}$} & Assignment & 12 & 31 & 31 & 38 & 39 & 29 & 180 \\
\hline & Collection & 11 & 39 & 42 & 59 & 60 & 24 & 235 \\
\hline \multirow{2}{*}{$\begin{array}{l}\text { Bupyeong District } \\
\text { (부평구) }\end{array}$} & Assignment & 11 & 29 & 29 & 33 & 39 & 29 & 170 \\
\hline & Collection & 10 & 36 & 37 & 38 & 40 & 24 & 185 \\
\hline \multirow{2}{*}{$\begin{array}{l}\text { Gyeyang District } \\
\text { (계양구) }\end{array}$} & Assignment & 7 & 19 & 16 & 20 & 26 & 17 & 105 \\
\hline & Collection & 7 & 23 & 27 & 24 & 26 & 15 & 122 \\
\hline \multirow{2}{*}{$\begin{array}{l}\text { Seo District } \\
\text { (서구) }\end{array}$} & Assignment & 14 & 31 & 33 & 41 & 40 & 25 & 184 \\
\hline & Collection & 12 & 40 & 42 & 55 & 45 & 26 & 220 \\
\hline \multirow{2}{*}{$\begin{array}{l}\text { Ganghwa County } \\
\text { (강화군) }\end{array}$} & Assignment & 2 & 2 & 2 & 3 & 5 & 6 & 20 \\
\hline & Collection & 4 & 5 & 5 & 6 & 6 & 4 & 30 \\
\hline \multirow{2}{*}{$\begin{array}{l}\text { Ongjin County } \\
\text { (옹진군) }\end{array}$} & Assignment & 0 & 1 & 0 & 1 & 2 & 2 & 6 \\
\hline & Collection & 0 & 2 & 3 & 2 & 1 & 1 & 9 \\
\hline \multirow{2}{*}{ Total } & Assignment & 36 & 89 & 89 & 107 & 110 & 80 & 1,000 \\
\hline & Collection & 68 & 216 & 240 & 282 & 277 & 143 & 1,226 \\
\hline
\end{tabular}

Table 2. Contents of questionnaire

\begin{tabular}{c|l|c}
\hline Category & \multicolumn{1}{c|}{ Contents } & Measurement type \\
\hline Status of use & $\begin{array}{l}\text { 1) Frequently used parks, 2) frequency and time of use, } \\
\text { 3) access and residence times, 4) transportation }\end{array}$ & Categorical type \\
\hline User satisfaction & $\begin{array}{l}\text { 1) Accessibility, 2) ease of use, 3) facility management status, } \\
\text { 4) safety, 5) landscape }\end{array}$ & $\begin{array}{c}\text { Continuous type } \\
\text { (Likert scale) }\end{array}$ \\
\hline Citizen participation plan & 1) Willingness to participate, 2) how to participate, & Categorical type \\
\hline Personal characteristics & Gender, age, occupation, income, residence, period of residence & Categorical type \\
\hline
\end{tabular}

간대 - 체류 기간 - 교통수단 - 접근 시간 등 기본적으로 도시공 원 이용실태를 조사할 때 사용하는 문항을 사용하여 조사하였 다(Kim and Cho, 2011; Lee and Kim, 2018). 두 번째 파트에 서는 공원 이용 만족도에 대한 조사를 위해 한강공원 이용 만 족도에 사용되는 27개 문항 중(Kim and Lee, 2019) 수변공원 및 선형공원에 적합한 문항을 제외한 문항을 설문지에 추가하 였다(접근성: 5문항, 이용 편리성: 6 문항, 시설관리상태: 6 문 항, 안전성: 5 문항, 조경 및 경관: 5 문항)(Table 4 참조). 세 번 째 파트에서는 시민참여 공원녹지 운영관리 실태를 탐색적으 로 파악하기 위해서 선호하는 도시녹화 방법, 바람직한 관리방
안, 녹지관리 참여 의사, 선호하는 참여 활동, 참여 의사 없는 이유 등으로 구성하였다. 해당 문항들은 인천시에서 사용하고 있는 공원녹지 시민설문조사를 바탕으로 하되, 새롭게 조성되 는 공원 및 개선된 관리방안 등은 추가하여 문항을 구성하였다. 네 번째 파트에서는 이용자들의 사회인구학적 조사를 위해 성 별, 연령대, 직업, 소득, 자녀 수, 거주지, 거주기간을 포함하여 구성하였다. 만족도 조사는 5점 만점의 리커트 척도(1점-전혀 그렇지 않다 5점-매우 그렇다)를 이용하였으며, 그 외 문항 은 명목형 척도로 수집하였다. 
Table 3. Demographic characteristics

\begin{tabular}{|c|c|c|c|}
\hline Variable & Sortation & $\begin{array}{l}\text { Frequency } \\
\text { (Person) }\end{array}$ & $\begin{array}{c}\text { Percentage } \\
(\%)\end{array}$ \\
\hline \multirow{2}{*}{ Gender } & Man & 632 & 51.5 \\
\hline & Woman & 594 & 48.5 \\
\hline \multicolumn{2}{|r|}{ Total } & 1,226 & 100.0 \\
\hline \multirow{6}{*}{ Age } & $14 \sim 19(10 \mathrm{~s})$ & 68 & 5.5 \\
\hline & $20 \sim 29(20 \mathrm{~s})$ & 216 & 17.6 \\
\hline & $30 \sim 39(30 s)$ & 240 & 19.6 \\
\hline & $40 \sim 49(40 s)$ & 282 & 23.0 \\
\hline & $50 \sim 59(50 \mathrm{~s})$ & 277 & 22.6 \\
\hline & 60 s or older & 143 & 11.7 \\
\hline \multicolumn{2}{|r|}{ Total } & 1,226 & 100.0 \\
\hline \multirow{11}{*}{ Occupation } & Professional occupation & 138 & 11.3 \\
\hline & Public officials and teachers & 311 & 25.4 \\
\hline & Production position & 44 & 3.6 \\
\hline & Student & 119 & 9.7 \\
\hline & Housewife & 132 & 10.8 \\
\hline & Technical office position & 204 & 16.6 \\
\hline & Service sales business & 54 & 4.4 \\
\hline & Self-employment & 68 & 5.5 \\
\hline & $\begin{array}{l}\text { Agriculture, forestry, } \\
\text { livestock, fishing }\end{array}$ & 3 & 0.2 \\
\hline & Not employed & 93 & 7.6 \\
\hline & Other & 60 & 4.9 \\
\hline \multicolumn{2}{|r|}{ Total } & 1,226 & 100.0 \\
\hline \multirow{6}{*}{ Income } & Less than a million won & 203 & 16.6 \\
\hline & $\begin{array}{l}\text { More than } 1 \text { million won } \\
\sim \text { under } 2 \text { million won }\end{array}$ & 200 & 16.3 \\
\hline & $\begin{array}{c}\text { More than } 2 \text { million won } \\
\sim \text { under } 3 \text { million won }\end{array}$ & 341 & 27.8 \\
\hline & $\begin{array}{c}\text { More than } 3 \text { million won } \\
\sim \text { under } 4 \text { million won }\end{array}$ & 228 & 18.6 \\
\hline & $\begin{array}{c}\text { More than } 4 \text { million won } \\
\sim \text { under } 5 \text { million won }\end{array}$ & 132 & 10.8 \\
\hline & More than 5 million won & 122 & 10.0 \\
\hline \multicolumn{2}{|r|}{ Total } & 1,226 & 100.0 \\
\hline \multirow{5}{*}{$\begin{array}{l}\text { Residence } \\
\text { period }\end{array}$} & Less than 5 years & 96 & 7.8 \\
\hline & $\begin{array}{l}\text { More than } 5 \text { years } \\
\text { to less than } 10 \text { years }\end{array}$ & 117 & 9.5 \\
\hline & $\begin{array}{l}\text { More than } 10 \text { years } \\
\text { to less than } 15 \text { years }\end{array}$ & 146 & 11.9 \\
\hline & $\begin{array}{l}\text { More than } 15 \text { years } \\
\text { to less than } 20 \text { years }\end{array}$ & 130 & 10.6 \\
\hline & More than 20 years & 737 & 60.1 \\
\hline \multicolumn{2}{|r|}{ Total } & 1,226 & 100.0 \\
\hline
\end{tabular}

\section{4. 통계분석 방법 및 절차}

통계분석 절차로는 첫째, 공원 이용자의 사회인구학적 특성 을 파악하기 위해서 빈도분석(frequency analysis)을 실시하였 다. 둘째, 공원 운영관리에 주요한 요인을 찾기 위해 다중회귀 분석을 실시하였다. 먼저 이용자의 특성(연령대, 소득, 거주기 간, 이용 빈도, 교통수단)을 1 단계로 투입한 후, 다음 만족도 조 사항목들의 요인 분석된 척도들을 2 단계로 투입하여(Table 5 참조) 관리 의지에 영향을 미치는 요인별 영향력을 조사하였 다. 마지막으로, 다중회귀분석에서 주요하게 나온 변수를 기준 으로 시민 특성별(연령대) 관리 참여 의지 및 방안을 알기 위 해 카이스퀘어 분석(Chisquare analysis)을 실시하였다(Table 6 참조). 통계절차는 SPSS Statistics Ver. 26.0 프로그램을 활 용하여 분석하였다.

\section{IV. 결과 및 논의}

\section{1. 조사대상자의 일반적 특성}

설문 인원수는 총 1,226명으로, 성별 비율은 남자가 $51.5 \%$ (632 명), 여자가 $48.5 \%$ (594명)로 남자가 다소 높은 비율을 보였다. 연령대는 40대가 23.0\%(282명), 50대가 22.6\%(277명), 30대가 $19.6 \%$ (240명), 20대가 17.6\%(216명), 60대 이상이 11.7\%(143명), 10 대가 5.5\%(68명)의 순으로 나타났으며, 전체적으로 30 50대 비중이 비교적 높은 비율을 보였다. 직업에는 '공무원 및 교사가 $25.4 \%$ (311명)로 가장 높은 비율의 응답률을 보였고 '기술사무직' 이 $16.6 \%$ (204명), '전문직'이 $11.3 \%$ (138명), '전업주부'가 $10.8 \%(132$ 명), '학생'이 9.7\%(119명) 순으로 다양한 직업이 비교적 고르게 나 타났다. 소득은 200만 원 300만 원 사이가 27.8\% (341명)로 높은 비중을 차지했다. 거주기간은 20년 이상이 $60.1 \%$ (737명)로 상당히 높은 비중으로 보인 것으로 보아, 대부분 응답자가 인천시에 오래 거주한 것으로 판단된다(자세한 내용은 Table 3 참조).

\section{2. 공원관리의지에 영향을 미치는 요인분석}

다중회귀분석을 실시하기에 앞서 요인을 축소하고 대표성을 가진 요인으로 구분하기 위하여 탐색적 요인분석을 실시하였 다. 요인분석은 주성분 분석의 Varimax 직각회전 방법을 사용 하였으며, 구성요인을 추출하기 위해 주성분 분석(principle component analysis)을 사용하였고, 요인 적재치는 0.4 이상을 기준으로 하였다. 
Table 4. Factor analysis(principal component analysis)

\begin{tabular}{|c|c|c|c|c|c|c|c|}
\hline Construct & Items & Mean & Std. & Loadings & Eig. & $\%$ of variance & Alpha \\
\hline \multirow{5}{*}{ Accessibility } & Sign board & 3.30 & 0.86 & 0.73 & 2.129 & 42.581 & 0.649 \\
\hline & Public transportation & 3.34 & 1.00 & 0.66 & & & \\
\hline & Walking access & 3.45 & 1.00 & 0.44 & & & \\
\hline & Vehicle access & 3.41 & 1.04 & 0.67 & & & \\
\hline & Car entrance & 3.17 & 1.06 & 0.72 & & & \\
\hline \multicolumn{8}{|c|}{$\mathrm{KMO}=.583$, Chi-square $=1,669.498, d f=10, p \chi .000$} \\
\hline \multirow{6}{*}{ Convenience } & Walking, running & 3.88 & 0.75 & 0.69 & 3.18 & 52.98 & 0.82 \\
\hline & Bicycle & 3.43 & 0.95 & 0.67 & & & \\
\hline & Sports facilities & 3.21 & 0.83 & 0.75 & & & \\
\hline & Rest area & 3.42 & 0.87 & 0.76 & & & \\
\hline & Public toilet & 3.39 & 0.89 & 0.75 & & & \\
\hline & Vulnerable population & 3.19 & 0.86 & 0.74 & & & \\
\hline \multicolumn{8}{|c|}{$\mathrm{KMO}=.858$, Chi-square $=2,193.711, d f=15, p \nless .000$} \\
\hline \multirow{6}{*}{ Facility conditions } & Trails & 3.67 & 0.77 & 0.78 & 3.77 & 62.88 & 0.88 \\
\hline & Sports facilities & 3.27 & 0.81 & 0.74 & & & \\
\hline & Rest area & 3.43 & 0.81 & 0.81 & & & \\
\hline & Public toilet & 3.40 & 0.87 & 0.80 & & & \\
\hline & Illegal banner & 3.47 & 0.86 & 0.77 & & & \\
\hline & Open spaces & 3.58 & 0.81 & 0.85 & & & \\
\hline \multicolumn{8}{|c|}{$\mathrm{KMO}=.886$, Chi-square $=538.067, d f=15, \not \chi .000$} \\
\hline \multirow{5}{*}{ Safety } & Pedestrian traffic & 3.69 & 0.78 & 0.81 & 3.35 & 66.95 & 0.88 \\
\hline & Sports facilities & 3.58 & 0.73 & 0.86 & & & \\
\hline & Night light & 3.55 & 0.79 & 0.80 & & & \\
\hline & Public toilet & 3.56 & 0.83 & 0.83 & & & \\
\hline & Risk of crime & 3.36 & 0.83 & 0.79 & & & \\
\hline \multicolumn{8}{|c|}{$\mathrm{KMO}=.855$, Chi-square $=2,993.173, d f=10, p \chi .000$} \\
\hline \multirow{5}{*}{$\begin{array}{l}\text { Landscape } \\
\text { / scenery }\end{array}$} & Landscape and waterscape & 3.72 & 0.74 & 0.84 & 3.75 & 75.02 & 0.92 \\
\hline & Natural affinity & 3.82 & 0.78 & 0.87 & & & \\
\hline & Harmonious with other facilities & 3.69 & 0.77 & 0.90 & & & \\
\hline & Planting maintenance & 3.72 & 0.82 & 0.89 & & & \\
\hline & Plenty of greenery & 3.50 & 0.90 & 0.83 & & & \\
\hline
\end{tabular}

Table 5. Result of multiple regression analysis

\begin{tabular}{|c|c|c|c|c|c|c|c|}
\hline \multirow{2}{*}{ Dependent variable } & \multirow{2}{*}{\multicolumn{2}{|c|}{ Independent variable }} & \multicolumn{2}{|c|}{ Unstandardized } & \multirow{2}{*}{$\begin{array}{l}\text { Std. } \\
\text { Beta }\end{array}$} & \multirow{2}{*}{$t$} & \multirow{2}{*}{ Sig. } \\
\hline & & & $\mathrm{B}$ & Std.error & & & \\
\hline \multirow{12}{*}{$\begin{array}{c}\text { Intention } \\
\text { to participation }\end{array}$} & \multicolumn{2}{|r|}{ (Constant) } & 1.794 & 0.199 & & 9.026 & \\
\hline & \multirow{5}{*}{ Model 1} & Age & 0.091 & 0.017 & 0.173 & 5.416 & 0.000 \\
\hline & & Income & -0.007 & 0.016 & -0.014 & -0.450 & 0.653 \\
\hline & & Duration of living & -0.024 & 0.017 & -0.041 & -1.374 & 0.170 \\
\hline & & Frequency & -0.037 & 0.018 & -0.069 & -2.022 & 0.043 \\
\hline & & Transportation & -0.009 & 0.012 & -0.025 & -0.731 & 0.465 \\
\hline & & \multicolumn{6}{|c|}{ Adjusted $\mathrm{R}^{2}=.036, F=8.580, p=.000$, Durbin-Watson $=2.114$} \\
\hline & \multirow{5}{*}{ Model 2} & Accessibility & 0.132 & 0.047 & 0.105 & 2.796 & 0.005 \\
\hline & & Convenience & 0.151 & 0.065 & 0.118 & 2.332 & 0.020 \\
\hline & & Facility maintenance & 0.146 & 0.071 & 0.120 & 2.063 & 0.039 \\
\hline & & Safety & -0.056 & 0.067 & -0.046 & -0.840 & 0.401 \\
\hline & & Landscape & 0.065 & 0.054 & 0.056 & 1.206 & 0.228 \\
\hline \multicolumn{8}{|c|}{ Adjusted $R^{2}=.122, F=15.007, p=.000$, Durbin-Watson $=2.098$} \\
\hline
\end{tabular}


Table 6. Chi-square result for park and green space management plan according to age

\begin{tabular}{|c|c|c|c|c|}
\hline Variable & $10 \sim 20 \mathrm{~s}$ & $30 \sim 40$ s & $50 \sim 60 \mathrm{~s}$ & $\mathrm{X}^{2} / p$ \\
\hline \multicolumn{4}{|c|}{ Preferred park type differences by age group } & \multirow{10}{*}{$\begin{array}{l}95.921 \\
/ .000^{* * *}\end{array}$} \\
\hline Coastal park & $54(4.4 \%)$ & $131(10.7 \%)$ & $114(9.3 \%)$ & \\
\hline Sports park & $32(2.6 \%)$ & $34(2.8 \%)$ & $19(1.5 \%)$ & \\
\hline Waterfront park & $25(2.0 \%)$ & $58(4.7 \%)$ & $53(4.3 \%)$ & \\
\hline History park & $7(0.6 \%)$ & $27(2.2 \%)$ & $29(2.4 \%)$ & \\
\hline Culture park & $47(3.8 \%)$ & $66(5.4 \%)$ & $25(2.0 \%)$ & \\
\hline Cemetery park & $2(0.2 \%)$ & $2(0.2 \%)$ & $5(0.4 \%)$ & \\
\hline Ecological park & $37(3.0 \%)$ & $61(5.0 \%)$ & $73(6.0 \%)$ & \\
\hline Pet park & $35(2.9 \%)$ & $17(1.4 \%)$ & $10(0.8 \%)$ & \\
\hline Forest recreation park & $45(3.7 \%)$ & $126(10.3 \%)$ & $92(7.5 \%)$ & \\
\hline \multicolumn{4}{|c|}{ The best way to green the city } & \multirow{7}{*}{$\begin{array}{l}27.079 \\
1.003^{* *}\end{array}$} \\
\hline Increase roadside trees and buffer green areas & $94(7.7 \%)$ & $202(16.5 \%)$ & $202(16.5 \%)$ & \\
\hline School/public office fence demolition project & $14(1.1 \%)$ & $23(1.9 \%)$ & $24(2.0 \%)$ & \\
\hline Private house fence tear down project & $11(0.9 \%)$ & $13(1.1 \%)$ & $11(0.9 \%)$ & \\
\hline Abandoned land priority reforestation project & $147(12.0 \%)$ & $255(20.8 \%)$ & $173(14.1 \%)$ & \\
\hline Greening of the building's roof wall & $17(1.4 \%)$ & $23(1.9 \%)$ & $8(0.7 \%)$ & \\
\hline Other & $1(0.1 \%)$ & $6(0.5 \%)$ & $2(0.2 \%)$ & \\
\hline \multicolumn{4}{|c|}{ Desirable management plan for parks } & \multirow{6}{*}{$\begin{array}{l}17.390 \\
/ .026^{*}\end{array}$} \\
\hline Citizen-led, administrative support & $60(4.9 \%)$ & $109(8.9 \%)$ & $89(7.3 \%)$ & \\
\hline Consignment to a specialized company & $93(7.6 \%)$ & $183(14.9 \%)$ & $120(9.8 \%)$ & \\
\hline Administrative authorities led, citizen support & $63(5.1 \%)$ & $120(9.8 \%)$ & $136(11.1 \%)$ & \\
\hline Administrative authorities manage & $67(5.5 \%)$ & $108(8.8 \%)$ & $75(6.1 \%)$ & \\
\hline Other & $1(0.1 \%)$ & $2(0.2 \%)$ & $0(0 \%)$ & \\
\hline \multicolumn{4}{|c|}{ If there is an opportunity to participate, how would you like to do it } & \multirow{9}{*}{$\begin{array}{l}\text { Multiple } \\
\text { responses }\end{array}$} \\
\hline Participate in tree planting & $150(7.1 \%)$ & $256(12.1 \%)$ & $185(8.7 \%)$ & \\
\hline Participation in fund-raising for park green space & $35(1.7 \%)$ & $76(3.6 \%)$ & $48(2.3 \%)$ & \\
\hline Break down fences, participate in alley greening & $37(1.7 \%)$ & $34(1.6 \%)$ & $27(1.3 \%)$ & \\
\hline Participation in the greening business & $50(2.4 \%)$ & $77(3.6 \%)$ & $75(3.5 \%)$ & \\
\hline Participate as a volunteer & $95(4.5 \%)$ & $134(6.3 \%)$ & $175(8.3 \%)$ & \\
\hline Participate in village gardening & $101(4.8 \%)$ & $199(9.4 \%)$ & $177(8.3 \%)$ & \\
\hline Participation in public hearings & $27(1.3 \%)$ & $70(3.3 \%)$ & $78(3.7 \%)$ & \\
\hline Other & $3(0.1 \%)$ & $7(0.3 \%)$ & $5(0.2 \%)$ & \\
\hline \multicolumn{4}{|c|}{ The main reason for not wanting to participate in park management } & \multirow{7}{*}{$\begin{array}{l}44.238 \\
/ .000^{* * *}\end{array}$} \\
\hline Don't know how to participate & $46(3.8 \%)$ & $113(9.2 \%)$ & $97(7.9 \%)$ & \\
\hline Lack of professional knowledge & $26(2.1 \%)$ & $80(6.5 \%)$ & $83(6.8 \%)$ & \\
\hline Don't have enough time & $132(10.8 \%)$ & $223(18.2 \%)$ & $129(10.5 \%)$ & \\
\hline Because of economic leeway & $35(2.9 \%)$ & $65(5.3 \%)$ & $63(5.1 \%)$ & \\
\hline Not interested & $32(2.6 \%)$ & $33(2.7 \%)$ & $31(2.5 \%)$ & \\
\hline Other & $13(1.1 \%)$ & $8(0.7 \%)$ & $17(1.4 \%)$ & \\
\hline
\end{tabular}

${ }^{*} p<0.05,{ }^{* *} p<0.01,{ }^{* * *} p<0.001$ 
Table 4에서 보듯이, 척도별 고유치 기준값(eigenvalues)이 접근성을 제외하고 모두 3.0 이상으로 나타났으며, 여러 변수 간 적합도를 나타내는 $\mathrm{KMO}$ (kaiser-meyer-olkin) 값은 모든 요인분석에서 0.5 이상으로 적합하다고 판단되었다(Kaiser, 1974). 요인별 신뢰계수는 모든 척도에서 0.6 이상으로 높게 나 타나, 도출된 요인들의 통계적 신뢰성이 확보되었다. 탐색적 요 인분석을 통해 제거된 항목 없이 총 27 개의 항목이 5 개의 요인 으로 구분되었다.

이후 본 연구에서 설정한 '연령대', '수입, '거주기간' 등의 사 회인구학적 요인과 공원 이용 만족도 요인('접근성’, '이용 편리 성', '시설관리상태', '공원 안전성', '조경 및 경관')이 공원관리 의지에 영향을 미치는지를 파악하기 위해 다중회귀분석을 실 시하였으며, 그 결과는 Table 5 와 같다. 본 회귀모형의 설명력 값은 0.122 로 낮게 나타났지만, 모형의 적합도(F값)는 15.007 , 유의확률은 $p \nmid .000$ 으로 나타났다. Durbin-Watson 값은 2.098로 자기상관관계가 없음을 확인하였다. 연령대는 $\beta=0.091$ ( $\not \alpha$ $0.000)$ 로 연령대가 한 단계 증가하면 공원관리의지가 0.091 만 큼 높아진다고 할 수 있다. 그 외에 접근성, 편의성, 시설관리상 태는 다 정 $(+)$ 의 관계로 공원관리의지에 영향을 미치지만, 방 문빈도의 경우에는 $\beta=-0.037$ ( $p<0.043)$ 으로 $\beta$ 부호가 부(-)적 이므로 방문빈도가 한단계 증가하면 공원관리의지가 미세하게 나마 0.037 만큼 감소하는 것으로 나타났다. 공원 이용 만족도 요인 중 전반적 만족에 가장 큰 영향을 미친 요인은 연령대( $\beta$ $=0.173, \not \chi .000)$ 로 나타났으며, 시설관리상태 $(\beta=0.120, \not \chi .05)$, 이용 편리성 $(\beta=0.118, p \times .05)$, 접근성 $(\beta=0.105, p \propto .05)$ 이 그 뒤를 이었다.

\section{3. 연령대별 공원운영관리 차이 비교분석}

다중회귀분석 결과, 공원 관리의지에 가장 큰 영향을 미친 ‘연령대' 요인이 높게 나타났으며, 본 연구에서 연령대별에 따 른 선홍공원 및 공원관리 의지 차이를 보기 위함이기 때문에, 카이스퀘어 분석을 통해서 연령대별 시민참여 공원녹지 운영 관리실태를 파악하였다. 해석의 유의미성을 높이기 위해서 10 20대, 30 40대, 50 60대 3가지 유형으로 나눠서 카이스 퀘어 분석을 실시하였다.

첫째, 시민들이 선호하는 도시공원에 10 20대, 30 40대, 50 60대 모두 씨사이드파크 등과 같은 해안공원의 선호도가 매우 높게 나타났다. 이는 젊은 층을 중심으로 전통적인 공원 의 모습이 아닌 수상 레크레이션 등을 즐길 수 있는 친수공간 의 확충 및 가족 집단을 위한 해양 치유프로그램과 같은 친환 경적인 프로그램이 필요함을 보여주었다.

둘째, 선호하는 도시녹화 방법에서 연령대별 차이가 유의하 게 나왔는데, 10 40대에서는 '버려진 땅에 대한 우선 녹화사업
추진'을 선호하였고, 50 60대 이상에서는 '도로변 가로수와 완 충녹지의 증대'가 가장 높은 비중을 차지하여 연령대별로 선호 하는 녹화 방법에 차이가 있음을 밝혀졌다. 이는 과거의 전통 적인 녹화방식이 아닌 최근에 게릴라 가드닝 및 도시재생 등과 같은 형태의 도시녹화가 빈번히 진행되고 있는 것과 무관하지 않다고 판단된다.

셋째, 시민들이 가장 바람직하다고 생각하는 공원녹지 관리 방안에 10 40대에서는 '전문업체 위탁관리'를 선호하였다. 그 리고 50 60대 이상 연령층에서는 '행정당국 주도 시민 자원봉 사'가 가장 높아, 연령이 높을수록 참여 의지가 높다는 것을 보 여주었다. 이는 10 40대 연령층이 모든 연령층에 비해서 가장 시간의 부족을 많이 느끼는 세대이기도 하며, 본인들이 실질적 으로 참여하기보다는 전문업체를 통한 관리를 선호한다고 판 단된다. 즉, 이 연령대를 참여 인력으로 끌어들이기는 단기간에 쉽지 않다고 판단되며, 반대로 행정에서 주도하지만, 시민이 보 조하는 역할을 선호하는 50대 이상 연령층의 역할이 중요할 것 으로 판단된다.

넷째, 공원녹지계획에 참여기회가 생긴다면 하고 싶은 방법 에 따른 차이에 있어서 10 20대, 30 40대, 50 60대 모두 1순 위 '나무 심기'와 2순위 '마을 정원 가꾸기'가 가장 높았다. 이는 정원가꾸기가 최근 경기도 및 서울시에서 진행하고 있는 시민 정원사 등의 프로그램과 도시농업 등의 홍보로 마을 정원 등에 관한 관심이 지속적으로 늘어나고 있음을 보여준다고 판단된 다. 3순위로 '자원봉사자 참여' 또한 높게 응답되었는데, 자발적 공원관리 참여의식을 높여 활용할 필요가 있다고 판단된다.

마지막으로, 공원녹지 운영관리에 참여 의사가 없는 이유로 모두 '시간이 부족해서'라고 응답하였으며, 이 중 30 40대의 응답 비율이 제일 높았다. 다음으로 '참여 방법을 몰라서'라고 응답하였다. 즉, 공원관리에 대해 관심과 유도를 끌어낼 방안을 마련할 필요가 있다고 판단된다.

이러한 사항들을 종합해보면, 시민들은 공원녹지 관리방안 의 중요성에 대해서 인식하고 있으나 시민 주도적 형태의 관리 방안보다 공원 관리 위탁 또는 시에서 주도하는 형태에 참여하 는 형태인 소극적인 참여에 그치고 있음을 보여줬다.

\section{V. 결론}

본 연구는 인천광역시에 광역적으로 존재하는 여러 공원을 대상으로 공원관리의지에 영향을 미치는 요소를 알고자 하였 으며, 특히 공원관리의지에 가장 영향을 많이 미치는 연령대 변수에 따른 공원관리 참여의지와 차별화된 공원관리방안을 도출하기 위해 수행되었다. 본 연구의 결과를 통해 도출한 시 사점은 다음과 같다.

첫째, 인천시 여건 및 특성에 부합하는 친환경적인 해안 공 
간을 부각시키는 공원조성과 적절한 관리방안을 제시해야 한 다. 대부분 모든 연령대에서 씨사이드파크 등과 같은 해안공원 의 선호도가 매우 높게 나타났는데, 이는 해안 경관 요소를 이 용한 공원의 수요가 높음을 의미한다. 해안가에 인접한 인천시 와 '물'이라는 자연경관 자원을 통해 내륙과는 다른 친환경적이 며 친수적인 도시공원의 조성 및 브랜드화가 필요하다고 판단 된다. 인천시는 과거 해안이 항만조성 위주의 개발이 중심이었 다면, 2000년대 이후로 인근 거주민의 여가 공간 제공 및 관광 활성화를 위한 해안공원이 조성되기 시작했는데(Chang, 2014), 이렇게 조성된 공원과 같이 해안 경관 자원을 활용한 다양한 친수공원 및 관련 프로그램을 개설하여 시민들의 공원에 대한 관심을 향상시켜 주도록 해야할 것이다.

둘째, 10 40대의 공원 관리 참여를 위한 다양한 인센티브 제공 방안이 필요하다. 이 연령대들은 공원녹지의 조성 및 관 리의 중요성에 대해서는 인식하고 있지만, 참여시간 부족 및 관심 부족으로 인해 직접적인 참여보다는 전문업체 위탁형식 관리를 선호하고 있었다. 젊은 계층은 학업이나 구직, 경제활동 등에 의해 공원 관리에 참여할 수 있는 시간이 부족하여 공원 녹지관리 참여가 쉽지 않으므로, 개선 활동 참여를 위한 프로 그램을 계획하고, 그에 따른 인센티브 부여를 통하여 공원녹지 개선 실천사업으로 이어져야 할 것이다. 예를 들어, 젊은 층은 공원 관리 참여기회가 마련되면 1순위로 나무 심기, 2순위로 마을 정원 가꾸기를 선호하는 것으로 보아, 1 인 1 나무 심기 행 사나 텃밭 가꾸기를 실시하고 그로 인한 에코마일리지 부여, 문화행사 할인 혜택이나 봉사활동 시간 인정 등 다양한 인센티 브 부여 방안이 강구되어야 할 것이다.

셋째, 공원 녹지사업 홍보 시 참여 방법 절차를 상세하게 명 시해야 한다. 50대 이상은 10 40대와는 다르게 행정당국의 주 도 여부를 막론하고 개인이 공원녹지 개선에 적극적으로 참여 하겠다는 비율이 높게 나타났다. 특히 60 대 이상은 녹화사업 홍보활동에 참여할 의향이 높은 것으로 나타났다. 하지만 참여 가 어려운 주된 이유가 '참여 방법을 잘 몰라서'인 것을 보면 공원마다 녹지사업 홍보 부스를 열어 설명회를 진행하거나, 지 자체 차원에서 문자메시지 등을 통한 적극적인 홍보를 시행하 여 시민들이 자발적으로 공원 및 녹지공간 개선에 참여할 수 있도록 유도할 필요가 있다.

도시공원은 조성까지가 끝이 아니라 그 이후 지속적인 관리 가 더욱 중요하다. 앞으로 시민들의 도시공원에 대한 옥구는 지속적으로 높아질 것이며, 이에 따른 엄청난 지자체의 공공예 산이 필요할 것으로 예상된다. 이를 일정부분 해결하기 위해서 단기적으로는 50대 이상의 집단을 우선적으로 고려한 적절한 관리 가이드라인 제공을 통해 공원관리를 높여가야 하며, 장기 적으로는 젊은층의 관심과 유도를 점차적으로 끌어내어 도시 공원의 유지관리범위를 확장시키고 관리방법을 다양화시켜 나
가야 할 것이다. 본 연구 결과는 연령과 같은 사회인구학적 요 인을 도시공원 운영 및 관리에 적극적으로 활용할 필요가 있음 을 제시해주는 연구임과 동시에 실무적으로 인천광역시에 추 후 공원을 신설하거나 리모델링시 기존 공원의 재정비에 필요 한 기초자료로써 사용될 수 있을 것이라 판단한다. 더 나아가 인천시를 비롯한 많은 지자체에서 추구하고 있는 도시공원 시 민참여를 활성화시키기 위해 향후 이용자의 연령을 포함한 다 양한 인구사회학적 요인을 통해 실현가능한 시민참여형 공원 관리 정책 수립 연구가 지속되어야 할 것이다.

\section{References}

1. Bae, M. G., and Y. R. Kim(2013) Development of urban park supply alternatives considering the equity evaluation of urban park service: Focused on Cheongju City. The Korea Spatial Planning Review, 49-66.

2. Byeon, J. S., I. H. Kim and S. H. Shin(2011) An institutional approach for application of the contracting-out in city parks - Focused on the case study of city park management of Seongnam City -. Journal of the Korean Institute of Landscape Architecture 39(5): 33-47.

3. Chang, H. J. (2014) Program and Space Design of Seafront Park Considering Landscape Management -A Case Study on Jinhaeru Seafront park- Master dissertation, Graduate School of Seoul National University).

4. Cho, W. R. (2012) A Study on the Effect of Place Attachment on Park Management in Citizen Participatory Community Park. Master Dissertation, Graduate School of Seoul National University.

5. da Schio, N., A. Phillips, K. Fransen, M. Wolff, D. Haase, S. K. Ostoić, and R. De Vreese(2021) The impact of the COVID-19 pandemic on the use of and attitudes towards urban forests and green spaces: Exploring the instigators of change in Belgium. Urban Forestry \& Urban Greening, 127305.

6. Guo, S., C. Song, T. Pei, Y. Liu, T. Ma, Y. Du, J. Chen, Z. Fan, X. Tang, Y. Peng and Y. Wang (2019) Accessibility to urban parks for elderly residents: Perspectives from mobile phone data. Landscape and Urban Planning, 191, 103642.

7. Ha, H. G. (2020) Changes in citizen participation policy in park and green administration: Focusing on Seoul, Incheon, Daegu, Ulsan, and Busan. GRI Review 22(4): 1-24.

8. Kaiser, H. (1974) An index of factorial simplicity. Psychometrika, 39(1): 31-36.

9. Kim, G. J. (2012) Welfare activation strategy for a urban park users. The Journal of the Korea Contents Association 12(10): 195-204.

10. Kim, J. H. (2015) A comparative research on citizen participation administration for good governance in large cities: Focusing on supporting policies for community building projects in Busan and Seoul. The Korean Journal of Local Government Studies 18(4): 135-170.

11. Kim, J. T., and J. H. Cho(2011) Recognition difference of local residents and tourists to urban park operation and management -With a special reference to the Wolmi Park in Incheon-. Journal of the Korean Institute of Landscape Architecture 25: 432-441.

12. Kim, K. H. (2003) Citizen participation in urban design: A need to create private not-for-profit organizations. Journal of Environmental Studies 41(4): 79-98.

13. Kim, M., J. Shim, H. Kim and Y. G. Kim(2009) A study of the management subject and the park user's mind for activating citizen's 
participation in the Seoul Forest Park management. Journal of Korea Planners Association 44(1): 223-234

14. Kim, S. K., and J. H. Lee(2019) A study on the park components affecting the satisfaction of park usage by user groups - Based on the analysis of the 2018 satisfaction survey of Hangang Park users -. Journal of the Korea Landscape Council 11(2): 21-33.

15. Kim, Y. I., J. G. Kim, J. S. An and A. H. Choi (2010). Citizen satisfaction model for urban parks and greens - A transactional approach in the case of Anyang City, Korea -. Journal of the Korean Institute of Landscape Architecture, 38(3), 62-74.

16. Kim, Y. K., and G. M. Nam (2019). A study on factors influencing the residents' participation of urban regeneration: Focused on the mediating effect of place attachment. Journal of the Korean Regional Development Association, 30(3), 43-65.

17. Kwon, J. J., D. H. Kim and H. Y. Hwang(2011) A dynamic analyses on the influences of the governance decisions for Cheong-ju Won-heungi Eco-Park. Journal of the Korean Institute of Landscape Architecture 39(1): 65-74.

18. Lee, D. Y.(2013) Influence Factors on Satisfaction with and Participating Attitude in Volunteer Work in Management of Urban Parks: Focused on Seoul Forest Volunteer Doctoral Dissertation, Graduate School of Seoul National University.

19. Lee, J. H.(2021) Differences in park use behavior and perception between groups by frequency of visit through comparison of Yangju Urban Parks in 2014 and 2020. Journal of the Korean Institute of Landscape Architecture 49(2): 41-50.

20. Lee, J. H. and S. K. Kim(2018) Extraction of essential design elements for urban parks - Based on the analysis of 2017 satisfaction survey of park Use in Seoul -. Journal of the Korean Institute of Landscape Architecture 46(6): 41-48.

21. Ly, T. P. and H. Xiao(2016) An innovative model of park governance: Evidence from Vietnam. Journal of Ecotourism 15(2): 99-121

22. Mertens, L., J. Van Cauwenberg, J. Veitch, B. Deforche and D. Van
Dyck(2019) Differences in park characteristic preferences for visitation and physical activity among adolescents: A latent class analysis. PLOS ONE 14(3): e0212920

23. Nam, J. V. and H. Kim(2019) Differential levels of governance and its impact on urban park management and users' satisfaction - The case of sheffield district parks, UK -. Journal of the Korean Institute of Landscape Architecture 47(4): 50-60.

24. Park, J. G. (2012) Strategy on the formation of the regional community-focus on the case of Cheonan. The Journal of the Korea Contents Association 12(7): 183-193.

25. Son, S. R. and B. G. Yoon(2002) A study on open space policy based on urban residents' values of open space. Journal of Korea Planning Association 37(4): 59-81.

26. Son, Y. H. (2011) Study on the meaning of national urban park system and the challenging in management operations - Focusing on the case of Japanese national government park system. Journal of Korea Planning Association 46(3): 79-92.

27. Subramanian, D. and A. Jana(2018) Assessing urban recreational open spaces for the elderly: A case of three Indian cities. Urban Forestry \& Urban Greening 35: 115-128.

28. Sundevall, E. P. and M. Jansson(2020) Inclusive parks across ages: Multifunction and urban open space management for children, adolescents, and the elderly. International Journal of Environmental Research and Public Health 17(24): 9357.

29. Wen, C., C. Albert and C. Von Haaren(2020) Equality in access to urban green spaces: A case study in Hannover, Germany, with a focus on the elderly population. Urban Forestry \& Urban Greening 55: 126820

30. Yoon, J. I., and J. H. Kim(2020) The influence of the perception of restorative environment on place attachment for visitors to Han River Park: Grounded on attention restoration theory. Korean Journal of Lesure, Recreation \& Park 44(3): 1-13.

\begin{tabular}{rll}
\hline Received : & 7 September, 2021 & \\
Revised : 7 October, 2021 & (1st) \\
& 9 November, 2021 & $(2 \mathrm{nd})$ \\
& 16 November, 2021 & $(3 \mathrm{rd})$ \\
Accepted : 16 November, 2021 & \\
3인익명 심사필 &
\end{tabular}

